\title{
Development of a new methodology for the preparation of optically active alcohols*
}

\author{
Pher G. Andersson \\ Department of Organic Chemistry, Uppsala University, Box 599, S-751 24 Uppsala, \\ Sweden
}

\begin{abstract}
This article summarizes our recent achievements in the asymmetric catalytic formation of chiral alcohols using 3-substituted, 2-azanorbornyl-based ligands. The use of this structural unit in ligand synthesis offers several advantages over the analogous proline chemistry, such as equal availability of both enantiomers and increased rigidity of the catalysts. This ligand has been found to be very useful for the two reactions described in this paper: the ruthenium-catalyzed transfer hydrogenation of ketones, and the base-mediated rearrangement of epoxides.
\end{abstract}

\section{INTRODUCTION}

It is now more than 35 years since Nozaki et al. prepared the first chiral ligand designed for asymmetric catalysis and used it in a copper-catalyzed, asymmetric cyclopropanation reaction [1]. Despite the tremendous development the field of catalytic asymmetric synthesis has experienced, there is still a need for development of new efficient ligands. When aiming at the design of a versatile ligand today, there are a number of criteria to keep in mind. The ligand should

(i) be easy to make in large scale from cheap starting materials,

(ii) be available in both enantiomeric forms,

(iii) have a stable and simple structure with a low molecular weight,

(iv) bind to a vareity of metals, and

(v) lead to high asymmetric induction in a number of different processes.

Few classes of chiral compounds have been so exploited in organometallic catalysis as the naturally occurring amino acids. Within this class of substances, proline-derived ligands have achieved particular interest due to the rigidity imposed by the pyrrolidine unit [2]. In light of the success of this structure in particular, we turned our attention to 2-azanorbornyl analogs with an even more restrained backbone. In addition to the increased rigidity, ligands based on this subunit are equally accessible in both enantiomeric forms, in contrast to natural amino acid derivatives.

The basis for the chemistry described in this account article was founded back in 1990 when the groups of Stella [3], Bailey [4], and Waldmann [5] independently reported on an efficient procedure for the asymmetric synthesis of 2-azanorbornyl-3-carboxylic esters 1. This synthesis utilizes cheap 1-phenylethylamine as a chiral auxiliary in an acid-catalyzed aza-Diels-Alder reaction between cyclopentadiene and an alkylglyoxylate imine (Fig. 1). The product is formed in a highly stereoselective manner and can easily be purified on a large scale.

\footnotetext{
*Plenary and invited lectures presented at the $12^{\text {th }}$ IUPAC International Symposium on Organometallic Chemistry Directed Towards Organic Synthesis (OMCOS-12), Toronto, Ontario, Canada, 6-10 July 2003. Other presentations are published in this issue, pp. 453-695.
} 


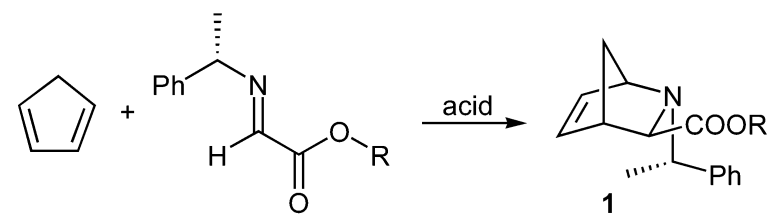

Fig. 1 The asymmetric aza-Diels-Alder reaction used for the synthesis of 2-azanorbornyl-3-carboxylic esters.

\section{RUTHENIUM-CATALYZED TRANSFER HYDROGENATION OF KETONES}

In one of our projects, we focused on the design of new ligands for ruthenium-catalyzed transfer hydrogenation of ketones into chiral secondary alcohols (Fig. 2) [6]. This reaction is industrially very interesting due to the many favorable properties of the reductant $i-\mathrm{PrOH}$ as compared to hydrogen gas.

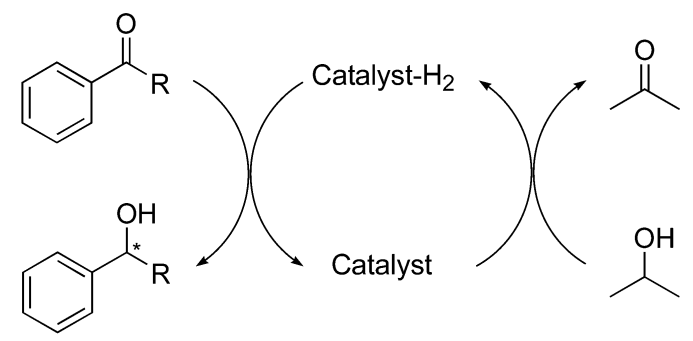

Fig. 2 The general principle for ruthenium-catalyzed transfer hydrogenation.

Our efforts in this field have been focused on the reduction of aromatic ketones. This reaction, for which there is a considerable amount of experimental data available [8,9], is well suited for probing the capabilities of new ligands, and the products themselves are important in organic synthesis. With our new bicyclic ligands readily available and in the light of the new findings by Noyori [10] that amino alcohols accelerate ruthenium-catalyzed transfer hydrogenations, we realized the potential of our ligands in this reaction. The 2-azanorbornyl-3-methanol system could be viewed as an extension of the prolinol ligand, a ligand that however gives a very low ee in the reduction of acetophenone [6].

In addition to the development of new 2-azanorbornyl-3-methanol ligands, we have also designated considerable efforts in order to clarify the mechanism of the reaction and to understand how the selectivity as well as the rate is affected by the ligand structure [11]. Experimentally, we have been able to merge several attractive features in our catalysts such as high asymmetric induction, a high rate of the reaction, and easily synthesized catalysts readily available in both enantiomeric forms.

A series of different ligands was prepared starting from two different aza-Diels-Alder adducts. The synthesis of the ligands is outlined in Schemes 1 and 2. In this catalytic reaction, the azanorbornyl ligands should have a secondary amine functionality in order to be effective. This reduces the number of steps in the synthesis since the nitrogen of the 2-azanorbornyl-3-methanol backbone does not have to be protected.

In the route to symmetrically substituted $\alpha$-carbons of the alcohol, $\mathbf{1}$ is treated with $\mathrm{H}_{2} /(\mathrm{Pd} / \mathrm{C})$ to yield the saturated $N$-deprotected amine $\mathbf{2}$ in $98 \%$ yield. This compound is then reduced by $\mathrm{LiAlH}_{4}$ in $90 \%$ yield to give the nonsubstituted ligand 4 . Alternatively, the ester can be dialkylated with the desired alkyl or aryl Grignard reagent to give the $\alpha, \alpha$-disubstituted tertiary alcohols. Using $\mathrm{MeMgBr}$, the overall yield of 5 is $64 \%$. For the preparation of $\alpha$-monosubstituted secondary alcohols, the $N$-protecting group is kept in the initial Pd/C-catalyzed reduction of the double bond ( $92 \%$ yield). The resulting saturated ester is then reduced to the alcohol by $\mathrm{LiAlH}_{4}$ followed by a Swern oxidation to give the corresponding aldehyde (92\% yield in 2 steps). At this stage, a number of different aryl and alkyl groups 


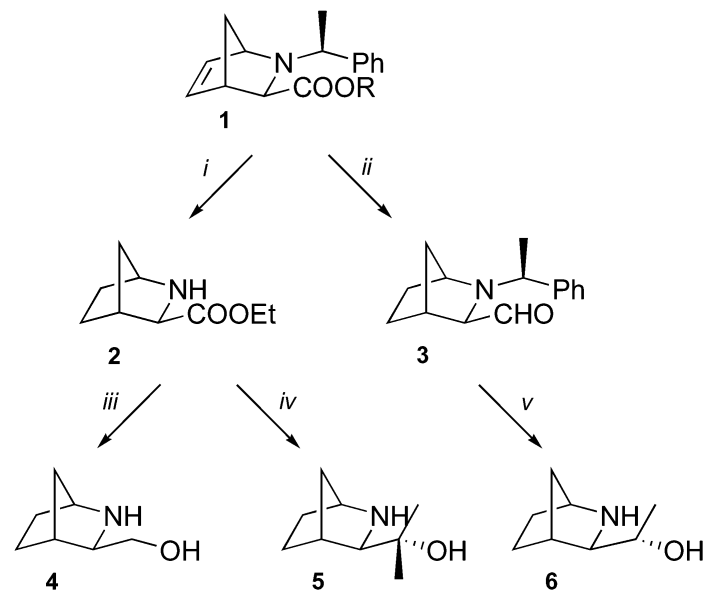

Scheme 1 ( i) $\mathrm{H}_{2}$ (10 atm), Pd/C, EtOH; (ii) $\mathrm{H}_{2}$ (1 atm), Pd/C, EtOH, rt.; LiAlH 4 , THF, rt.; Swern oxidation; (iii) $\mathrm{LiAlH}_{4}$, THF; (iv) (a) $\mathrm{PhCH}_{2} \mathrm{Br}, \mathrm{K}_{2} \mathrm{CO}_{3}, \mathrm{CH} 3 \mathrm{CN}$; (b) $\mathrm{MeMgBr}, \mathrm{THF}$; (c) $\mathrm{H}_{2}$ (10 atm), Pd/C, EtOH; (v) (a) $\mathrm{MeMgBr} / \mathrm{CeCl}_{3}$, THF, $-78{ }^{\circ} \mathrm{C}$; (b) $\mathrm{H}_{2}(20 \mathrm{~atm}), \mathrm{Pd}(\mathrm{OH})_{2} / \mathrm{C}, \mathrm{EtOH}, \mathrm{rt}$.

can be added in a highly diastereoselective manner by use of a Grignard reagent in combination with $\mathrm{CeCl}_{3}$. In this study, we used $\mathrm{MeMgBr}$, which gave the final ligand in $98 \%$ yield.

The other diastereomer of the $\alpha$-monosubstituted secondary alcohols was prepared from the azaDiels-Alder adduct 7 (Scheme 2). This compound was subjected to Pd/C-catalyzed hydrogenation of the double bond followed by a diastereoselective $\mathrm{LiAlH}_{4}$ reduction of the ketone to the corresponding alcohol which was $N$-deprotected by hydrogenolysis to give ligand $\mathbf{8}$.

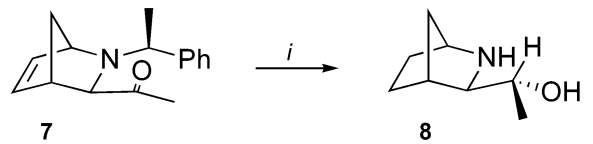

Scheme 2 (i) $\mathrm{H}_{2}$ (1 atm), $\mathrm{Pd} / \mathrm{C}, \mathrm{MeOH}, \mathrm{K}_{2} \mathrm{CO}_{3}$, rt.; $\mathrm{LiAlH}_{4}, \mathrm{THF},-78{ }^{\circ} \mathrm{C}$.; $\mathrm{H}_{2}(20 \mathrm{~atm}), \mathrm{Pd}(\mathrm{OH})_{2} / \mathrm{C}, \mathrm{EtOH}$, rt.

Ligands 4-6 and 8 were evaluated in the transfer hydrogenation of acetophenone, using $\left[\mathrm{RuCl}_{2}(p\right.$-cymene)] and isopropoxide as base (acetophenone:Ru:chiral ligand:i-PrOK, 200:1:4:5) [12]. The results are summarized in Table 1, entries 1-4.

Table 1 Asymmetric transfer hydrogenation of acetophenone using ligands 4-6 and 8 .<smiles>CC(=O)c1ccccc1</smiles>

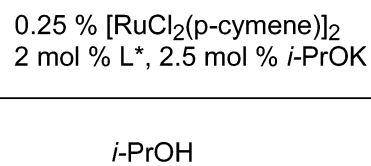

\begin{tabular}{lcccccc}
\hline & & \multicolumn{5}{c}{ Product } \\
\cline { 3 - 6 } Entry & Chiral ligand & Conv. $(\%)$ & $\mathrm{t}(\mathrm{h})$ & ee $(\%)$ & Config. & TOF $\left(\mathrm{h}^{-1}\right)$ \\
\hline 1 & 4 & 92 & 1.5 & 94 & $\mathrm{~S}$ & 450 \\
2 & 5 & 85 & 16 & 0 & - & 20 \\
3 & 6 & 88 & 4.5 & 89 & $\mathrm{~S}$ & 80 \\
4 & 8 & 97 & 0.5 & 94 & $\mathrm{~S}$ & 1330 \\
\hline
\end{tabular}


It was found that just by introducing a methyl substituent in $\alpha$-position to the alcohol, the selectivity and the rate of the new ligands changed from a very active catalytic species [for the $(R)$-Me substitution, 8] to a less active one [ $(S)$-Me substitution, 6]. This could be explained by steric interactions between the substituent and the arene or between the substituent and the Ru-hydride in the metal hydride complex.

We showed earlier that a remote dimethyl dioxolane structure on 2-azanorbornyl methanol causes a significant increase in the activity of the catalyst [13]. If the positive effect of this modification was transferable to a ligand with a $(R)$-methyl substituent at the carbinol carbon, we would obtain an extremely efficient catalyst. The synthesis of ligand $\mathbf{1 0}$ (Scheme 3 ) starts with the dihydroxylation of $\mathbf{1}$ by using $\mathrm{OsO}_{4}$ and $\mathrm{NMO}$ in a ${ }^{t} \mathrm{BuOH} / \mathrm{H}_{2} \mathrm{O}$ mixture. Protection of the diol with a dimethyl ketal, in the presence of $p$-TsOH afforded the corresponding dioxolane. Reduction of the ester with $\mathrm{LiAlH}_{4}$ followed by Swern oxidation to afforded aldehyde 9 in $84 \%$ yield. Grignard reaction with $\mathrm{MeMgBr}$ and $\mathrm{CeCl}_{3}$ and subsequent debenzylation furnished the desired ligand $\mathbf{1 0}$.

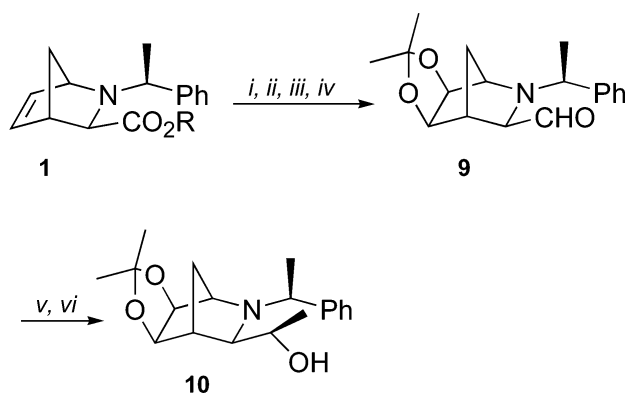

Scheme 3 (i) $1 \mathrm{~mol} \% \mathrm{OsO}_{4}, \mathrm{NMO},{ }^{t} \mathrm{BuOH} / \mathrm{H}_{2} \mathrm{O}, \mathrm{RT}, 12 \mathrm{~h}$; (ii) p-TsOH, $\left(\mathrm{CH}_{3} \mathrm{O}\right)_{2} \mathrm{C}\left(\mathrm{CH}_{3}\right)_{2}, \mathrm{MeOH}, 50{ }^{\circ} \mathrm{C}, 12 \mathrm{~h}$, $89 \%$ (steps $i$ and ii); (iii) $\mathrm{LiAlH}_{4}$, THF, $0{ }^{\circ} \mathrm{C}, 1 \mathrm{~h}$; (iv) DMSO, oxalyl chloride, TEA, $\mathrm{CH}_{2} \mathrm{Cl}_{2}, 78{ }^{\circ} \mathrm{C}, 84 \%$ (steps iii and iv); (v) $\mathrm{MeMgBr}, \mathrm{CeCl}_{3}$, THF, $78{ }^{\circ} \mathrm{C}, 89 \%$; (vi) DMSO, oxalyl chloride, TEA, $\mathrm{CH}_{2} \mathrm{Cl}_{2}, 78{ }^{\circ} \mathrm{C}, 86 \%$; (v) $\mathrm{LiAlH}_{4}, \mathrm{THF}, 0{ }^{\circ} \mathrm{C}, 1 \mathrm{~h}$, and separation of the diastereomers; (vi) $30 \mathrm{wt} \%\left[\mathrm{Pd}(\mathrm{OH})_{2}\right], \mathrm{H}_{2}(1 \mathrm{~atm}), \mathrm{MeOH}, 50{ }^{\circ} \mathrm{C}$, $12 \mathrm{~h}, 38 \%$ (steps $v$ and $v i$ ).

When reducing acetophenone with $\mathbf{1 0}$ at an S/C ratio of 200:1 (Ru/ligand/base/substrate 1:4:5:200), the reaction was completed within 6 min with $96 \%$ ee. This result encouraged us to decrease the catalyst loading and it was found that at an S/C ratio of 1000:1 the reaction was finished in less than $15 \mathrm{~min}$, with a $\mathrm{TOF}_{50}$ as high as $8500 \mathrm{~h}^{-1}$. Even at an S/C ratio of 5000:1, the reaction proceeded to full conversion after $90 \mathrm{~min}$, but at an S/C ratio of 7000:1, the reaction stopped at $85 \%$ conversion. The enantioselectivity was unaffected by lowering the amount of catalyst, and no decrease in ee was detected as a result of prolonged reaction times.

The substrate study (Table 2) shows that it is possible to perform transfer hydrogenation on a range of different aromatic ketones with a catalyst loading as low as S/C 1000:1 (Table 2, entries 2, 3, $4,7,8$, and 10). Lowering the amount of catalyst does not affect the enantioselectivity, and the reaction rates are still high. This system is capable of reducing aromatic ketones that contain both electron-donating and -withdrawing substituents in ortho, meta, and para positions with excellent enantioselectivity. 
Table 2 Asymmetric transfer hydrogenation of aromatic ketones using ligand $\mathbf{1 0 .}$

\begin{tabular}{rlrcrc}
\hline Entry & \multicolumn{1}{c}{ Ketone } & $\mathrm{S} / \mathrm{C}$ & $\mathrm{t}(\mathrm{min})$ & conv $(\%)$ & ee $(\%)$ \\
\hline 1 & Isobutyrophenone & 200 & 30 & 93 & 90 \\
2 & 2-Methyl acetophenone & 1000 & 15 & 100 & 94 \\
3 & 2-Bromo acetophenone & 1000 & 10 & 98 & 95 \\
4 & 3-Methyl acetophenone & 1000 & 15 & 90 & 96 \\
5 & 3-Methoxy acetophenone & 200 & 4 & 100 & 98 \\
6 & 3-Amino acetophenone & 200 & 4 & 98 & 99 \\
7 & 3-Nitro acetophenone & 1000 & 15 & 100 & 91 \\
8 & 4-Chloro acetophenone & 1000 & 15 & 90 & 92 \\
9 & 2-Acetyl pyridine & 200 & 15 & 90 & 91 \\
10 & 3-Acetyl pyridine & 200 & 4 & 98 & 89 \\
11 & 4-Acetyl pyridine & 200 & 3 & 97 & 91 \\
\hline
\end{tabular}

\section{ASYMMETRIC BASE-MEDIATED REARRANGEMENT OF EPOXIDES}

Chiral allylic alcohols are synthetically very important and are widely applied in organic synthesis. These alcohols are generally prepared from $\alpha, \beta$-unsaturated ketones by fairly expensive hydride reductions or by kinetic resolution using the Sharpless epoxidation. A more efficient approach to chiral allylic alcohols is the base induced asymmetric rearrangements of meso-epoxides [14]. As a consequence, this transformation has been employed (using a stoichiometric amount of chiral diamine however) as the key step in the syntheses of numerous commercially and biologically important substances, e.g., carbovir [15], lasiol [16], faranal [17], leukotrienes [18], and prostaglandin precursors [19]. The corresponding catalytic reaction is less developed, and thus, this is an area where new methods are highly appreciated. Up to date, the most successful examples rely on the use of a chiral diamine as catalyst and LDA as the stoichiometric base. We have recently developed a new chiral diamine (Fig. 3) which accomplishes this transformation catalytically in high yield and enantioselectivity [20].

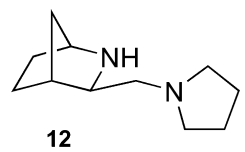

Fig. 3 The new chiral diamine used in the rearrangement of meso-epoxides into chiral allylic alcohols.

By the use of this new base, we could overcome several of the problems encountered with the former systems. Our base is easily synthesized, readily available in both enantiomeric forms and could most importantly be used in catalytic amounts without any severe lowering of neither the enantiomeric excess nor the yield of the reaction.

The synthesis of the bicyclic diamine start from the ester of the commonly employed azaDiels-Alder adduct 1 (Scheme 4). The carbon-carbon double bond in this compound is reduced, and the ester group of the resulting saturated product is subjected to $\mathrm{LiAlH}_{4}$ reduction followed by Swern oxidation in order to give the corresponding aldehyde $\mathbf{3}$. Reductive amination of this intermediate followed by hydrogenolysis of the $N$-protecting group leads to the desired chiral diamine $\mathbf{1 2}$. 


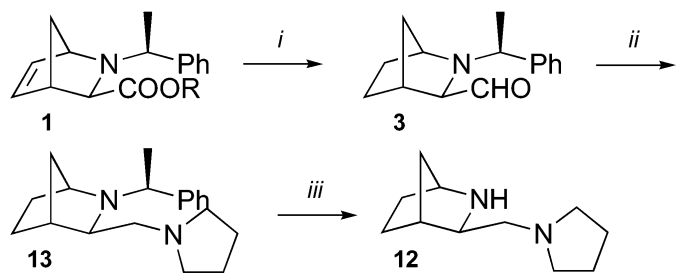

Scheme 4 ( $i$ ) (1) $\mathrm{H}_{2}$ (1 atm), Pd/C, EtOH, rt, (2) $\mathrm{LiAlH}_{4}$, THF, rt, (3) Swern oxidation; (ii) pyrrolidine or piperidine, MS $3 \AA$ A, $\mathrm{MeOH}$, then $\mathrm{NaBH}_{3} \mathrm{CN}$; (iii) $\mathrm{H}_{2}(1 \mathrm{~atm}), \mathrm{Pd}(\mathrm{OH})_{2} / \mathrm{C}, \mathrm{MeOH} / \mathrm{HOAc}$.

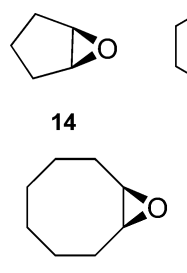

17<smiles>C1CCC2OC2C1</smiles>

15<smiles>C1CCC2OC2CC1</smiles>

16

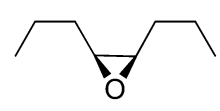

18

Fig. 4 meso-Epoxides evaluated in the catalytic rearrangement to chiral allylic alcohols.

The catalytic ability of the new base was evaluated using the conditions developed by Asami [21], that is, the reactions were carried out by adding a solution of the meso-epoxide to a catalyst mixture containing LDA as the stoichiometric base and DBU as cosolvent in THF. The results are presented in Table 3. The levels of asymmetric induction for the cyclic epoxides are, to our knowledge, the highest reported so far for the asymmetric epoxide deprotonation (entries 1-5, Table 3). It is also the first example of a catalytic system for this reaction which, except for cyclopentene oxide (entry 1, Table 3), gives very high enantioselectivity regardless of whether a full equivalent or $5 \mathrm{~mol} \%$ of the chiral base is used (cf. entries 2-5, Table 3).

Table 3 The enantiomeric excesses in the catalytic rearrangement of meso-epoxides using diamine $\mathbf{1 2}$.

\begin{tabular}{lccc}
\hline Entry & Epoxide & $\begin{array}{c}\text { ee }(1.2 \text { equiv } \\
\text { of diamine })\end{array}$ & $\begin{array}{c}\text { ee }(0.05 \text { equiv } \\
\text { of diamine })\end{array}$ \\
\hline 1 & 14 & 95 & $49^{\mathrm{a}}$ \\
2 & 15 & 97 & 96 \\
3 & 16 & 98 & 96 \\
4 & 17 & 81 & 78 \\
5 & 18 & 67 & 66 \\
\hline
\end{tabular}

${ }^{\mathrm{a}} 0.15$ equiv of the diamine used.

However, despite the generality and efficiency of 12, acyclic epoxides and some cyclopentene oxides could not be satisfactorily rearranged under catalytic conditions.

As a continuation of our attempts towards a systematic variation of the tertiary amine moiety, the trans-2,5-dialkylpyrrolidines 19 and $\mathbf{2 0}$ (Fig. 5) were judged as suitable catalyst candidates [22]. The limited flexibility of the pyrrolidine ring was an attractive feature, as well as the $C_{2}$-symmetry, which does not allow the formation of diastereomerically heterogeneous catalysts. Furthermore, the access to both enantiomers of the dimethylpyrrolidine would not only provide information about the influence of steric hindrance, but also reveal the preferred stereochemistry of the substituents at the $3^{\circ}$ amine. 


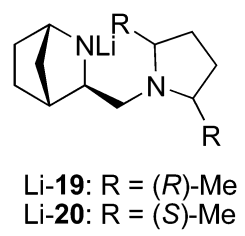

Fig. 5 The $2^{\text {nd }}$ generation chiral diamines used in the base-mediated rearrangement of meso-epoxides.

The diamines 19 and $\mathbf{2 0}$ were prepared by the previously described method, in which aminoester $\mathbf{1}$ was converted into the common intermediate $N$-Boc-amino acid $\mathbf{2 1}$ via hydrogenation, hydrolysis, and subsequent $N$-protection (Scheme 5). Enantiopure trans-2,5-dimethylpyrrolidines, synthesized from commercially available diols [23], were then attached via standard amide coupling to give $\mathbf{2 2}$ and $\mathbf{2 3}$. Deprotection and reduction then afforded $\mathbf{1 9}$ and $\mathbf{2 0}$ in good overall yields.
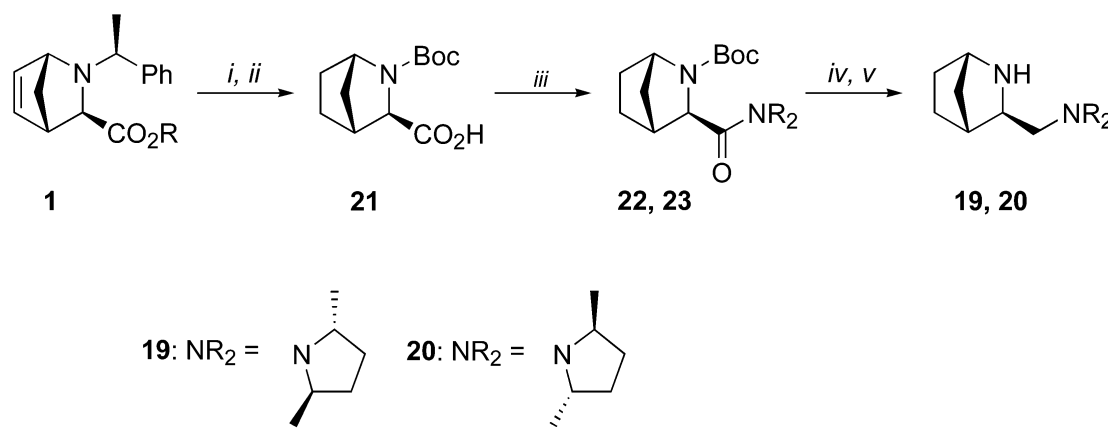

Scheme 5 (i) $\mathrm{H}_{2}$ (5 atm), $\mathrm{Pd} / \mathrm{C}$; (ii) $\mathrm{LiOH}$, then $\mathrm{Boc}_{2} \mathrm{O}$ (90\% for $\left.i-i i\right)$; (iii) EDC, $\mathrm{HOBt}, \mathrm{Et}_{3} \mathrm{~N}, \mathrm{R}_{2} \mathrm{NH}, \mathrm{CH}_{2} \mathrm{Cl}_{2}$ (76-95\%); (iv) $\mathrm{HCl}$ in dioxane; (v) LAH, THF (85-95\% for $i v-v)$.

It turned out that the combination of chirality in the bicycle and the pyrrolidine was matched in $\mathbf{1 9}$ and mismatched in $\mathbf{2 0}$. To test $\mathbf{1 9}$ for substrate generality, a series of representative meso-epoxides were subjected to the standard catalytic conditions, as outlined in Table 4. It was found that its efficiency applies to all substrates investigated, and the levels of enantioselectivities were improved. The result obtained with cyclopentene oxide (Table 4, entry 1) constitutes a new milestone in the field of asymmetric epoxide rearrangement, and is worthy of further comment. Cyclopentene oxide is a notori-

Table 4 The catalytic rearrangement of meso-epoxides using diamines 12 and 19.

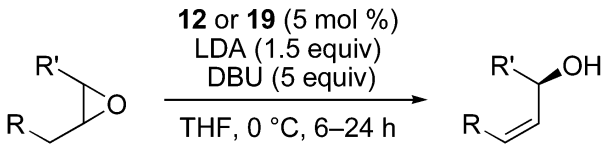

\begin{tabular}{lccccc}
\hline & & \multicolumn{2}{c}{$\mathbf{1 2}$} & \multicolumn{2}{c}{$\mathbf{1 9}$} \\
\cline { 3 - 6 } Entry & Epoxide & Yield \% & ee \% & Yield \% & ee \% \\
\hline 1 & 14 & 67 & $49^{\mathrm{a}}$ & 81 & 96 \\
2 & 15 & 91 & 96 & 95 & 99 \\
3 & 16 & 89 & 96 & 93 & $>99$ \\
4 & 18 & 82 & 66 & 80 & 91 \\
\hline
\end{tabular}

${ }^{\mathrm{a}} 0.15$ equiv of the diamine used. 
ously difficult substrate for the title reaction, which tends to undergo unclean syn- $\beta$-elimination due to competing $\alpha$-lithiation. However, in the presence of only $5 \mathrm{~mol} \%$ of 19, rearrangement takes place smoothly and furnishes cyclopentenol in $96 \%$ ee. Likewise, the catalytic rearrangement of acyclic epoxides to give $>90 \%$ ee is also purely novel.

\section{ACKNOWLEDGMENTS}

This work was supported by the Swedish Natural Research Council (NFR), the Swedish Research Council for Engineering Sciences (TFR), and the Swedish Council for Strategic Research (SSF). Dr. Mark Burk, Chirotech Ltd., is acknowledged for a generous gift of enantiopure diols. We are grateful to Dr. Peter Brandt for many valuable discussions.

\section{REFERENCES}

1. H. Nozaki, S. Moriuti, H. Takaya, R. Noyori. Tetrahedron Lett. 5239 (1966).

2. G. M. Coppola and H. F. Schuster. Asymmetric Synthesis: Construction of Chiral Molecules Using Amino Acids, pp. 267-345, John Wiley, New York (1987).

3. L. Stella, H. Abraham, J. Feneu-Dupont, B. Tinant, J. P. Declercq. Tetrahedron Lett. 31, 2603 (1990).

4. P. D. Bailey, R. D. Wilson, G. R. Brown. J. Chem. Soc., Perkin Trans. 11337 (1991).

5. H. Waldmann and M. Braun. Liebigs Ann. Chem. 1045 (1991).

6. (a) D. A. Alonso, D. Guijarro, P. Pinho, O. Temme, P. G. Andersson. J. Org. Chem. 63, 2749 (1998).

7. R. Noyori and S. Hashiguchi. Acc. Chem. Res. 30, 97 (1997).

8. S. Gladiali and G. Mestroni. Transition Metals for Organic Synthesis, M. Beller and C. Bolm (Eds.), Vol. 2, pp. 97-119, Wiley-VCH, Weinheim (1998).

9. M. Palmer, T. Walsgrove, M. Wills. J. Org. Chem. 62, 5226 (1997).

10. J. Takehara, S. Hashiguchi, A. Fujii, S. Inoue, T. Ikariya, R. Noyori. Chem. Commun. 233 (1996).

11. D. A. Alonso, P. Brandt, S. J. M. Nordin, P. G. Andersson. J. Am. Chem. Soc. 121, 9580 (1999).

12. D. A. Alonso, S. J. M. Nordin, P. Roth, T. Tarnai, P. G. Andersson. J. Org. Chem. 65, 3116 (2000).

13. S. J. M. Nordin, P. Roth, T. Tarnai, D. A. Alonso, P. Brandt, P. G. Andersson. Chem. Eur. J. 7, 1431 (2001).

14. For a review, see: A. Magnus, S. K. Bertilsson, P. G. Andersson. Chem. Soc. Rev. 31, 223 (2002).

15. (a) D. M. Hodgson, J. Whiterington, B. A. Moloney. J. Chem. Soc. Perkin Trans. 1, 3373 (1994);

(b) D. M. Hodgson and A. R. Gibbs. Synlett 657 (1997); (c) M. Asami, J. Takahashi, S. Inoue. Tetrahedron: Asymmetry 5, 1649 (1994); (d) P. Saravanan and V. K. Singh. Tetrahedron Lett. 39, 167 (1998).

16. T. Kasai, H. Watanabe, K. Mori. Bioorg. Med. Chem. 1, 67 (1993).

17. K. Mori and N. Murata. Liebigs Ann. 2089 (1995).

18. (a) J. S. Sabol and R. J. Cregge. Tetrahedron Lett. 30, 3377 (1989); (b) R. Hayes and T. W. Wallace. Tetrahedron Lett. 31, 3355 (1990).

19. (a) M. Asami. Chem. Lett. 5803 (1985); (b) M. Asami. Bull. Chem. Soc. Jpn. 63, 721 (1990); (c) M. Asami and S. Inoue. Tetrahedron 51, 11725 (1995); (d) D. Bhuniya, A. DattaGupta, V. K. Singh. J. Org. Chem. 61, 6108 (1996); (e) P. Saravanan and V. K. Singh. Tetrahedron Lett. 39, 167 (1998).

20. M. Södergren and P. G. Andersson. J. Am. Chem. Soc. 120, 10760 (1998).

21. (a) M. Asami, T. Ishizaki, S. Inoue. Tetrahedron: Asymmetry 5, 793 (1994); (b) M. Asami, T. Suga, K. Honda, S. Inoue. Tetrahedron Lett. 38, 6425 (1997). 
22. S. K. Bertilsson, M. Södergren, P. G. Andersson. J. Org. Chem. 67, 1567 (2002).

23. R. P. Short, R. M. Kennedy, S. Masamune. J. Org. Chem. 54, 1755 (1989). 